\title{
PRODUÇÃO DE FENOL-OXIDASES PELO FUNGO Pleurotus sajor-caju PS-2001 EM BIORREATOR AIRLIFT DE CIRCULAÇÃO INTERNA
}

\author{
F. BETTIN ${ }^{1}$, F. COUSSEAU ${ }^{1}$, K. MARTINS ${ }^{1}$, S. ZACCARIA ${ }^{1}$, \\ G.G.S. CUNHA ${ }^{1}$, M.M. da SILVEIRA ${ }^{1}$ e A.J.P. DILLON ${ }^{1}$ \\ ${ }^{1}$ Universidade de Caxias do Sul, Instituto de Biotecnologia \\ Laboratório de Enzimas e Biomassas - Laboratório de Bioprocessos \\ E-mail para contato: fbettin@ucs.br
}

\begin{abstract}
RESUMO - Fenol-oxidases são enzimas com elevado potencial de aplicação industrial por serem não específicas com relação ao substrato e capazes de oxidar compostos com estruturas semelhantes à lignina. Neste estudo, avaliou-se a produção de fenol-oxidases de Pleurotus sajor-caju PS-2001 em biorreator airlift de circulação interna utilizando diferentes volumes de meio de cultivo $(4,4,5$ e 5 L) e vazões de ar $\left(1,1,5\right.$ e $\left.2 \mathrm{~L} \cdot \mathrm{min}^{-1}\right)$ em $\mathrm{pH} 6,5$ a $28^{\circ} \mathrm{C}$. Dentre as condições testadas, 4,5 L de meio com aeração de $1,5 \mathrm{~L} \cdot \mathrm{min}^{-1}$ foi considerada a mais favorável à produção enzimática, visto que atividades de lacases (Lac), que representam as principais enzimas produzidas pelo fungo utilizado, atingiram 156 U.mL ${ }^{-1}$ em $90 \mathrm{~h}$ de cultivo; neste ensaio, também foram detectados os títulos máximos de peroxidases totais (Per) e de manganês peroxidases $(\mathrm{MnP})$, de $31 \mathrm{e}$ $21 \mathrm{U} \cdot \mathrm{mL}^{-1}$, respectivamente. Em $5 \mathrm{~L}$ de meio com aeração de $1 \mathrm{~L} \cdot \mathrm{min}^{-1}$, as atividades de Lac e Per atingiram níveis de 132 e 12 U.mL ${ }^{-1}$, respectivamente, ambas em $90 \mathrm{~h}$ de cultivo. MnP mostraram títulos elevados também em $4 \mathrm{~L}$ de meio com aeração de 1 L.min ${ }^{-1}\left(17\right.$ U.mL $L^{-1}$ em 24 h). Lignina peroxidases e oxidases do álcool veratrílico praticamente não foram detectadas. Concentrações superiores de biomassa ocorreram em $4,5 \mathrm{~L}$ de meio com aeração de $2 \mathrm{~L} \cdot \mathrm{min}^{-1}$ $\left(4,6\right.$ g.L $\mathrm{L}^{-1}$ em $\left.72 \mathrm{~h}\right)$ e em $4 \mathrm{~L}$ de meio com aeração de 1 L.min ${ }^{-1}\left(3,6\right.$ g.L $\mathrm{L}^{-1} \mathrm{em} 72$ h). O comportamento cinético mostrou consumos de substrato e de oxigênio dissolvido em todos os ensaios realizados.
\end{abstract}

\section{INTRODUÇÃO}

As principais fenol-oxidases incluem manganês peroxidases (MnP), lignina peroxidases (LiP) e lacases (Lac), que são secretadas no meio extracelular de crescimento dos fungos ligninolíticos em resposta a baixos níveis de fontes de nutrientes, principalmente carbono e nitrogênio (Gill e Arora, 2003). Lac e MnP catalisam a oxidação dos componentes fenólicos da lignina, enquanto LiP é muito eficiente na oxidação de substâncias fenólicas e não fenólicas (Min et al., 2001). Enzimas ligninolíticas são não específicas com relação ao substrato, permitindo aos microrganismos produtores a capacidade de degradar compostos com estruturas semelhantes à lignina, como fenóis, corantes, hidrocarbonetos policíclicos aromáticos, dioxinas e pesticidas. Suas potenciais aplicações incluem segmentos das indústrias de alimentos e bebidas, de petróleo, cosmética, química, farmacêutica e, especialmente, têxtil e de papel e celulose, (Canet et al., 2001; Dhawan et al., 2005; Couto e 
Herrera, 2006; Munari et al., 2007; Schmitt et al., 2012). O mecanismo não específico de atuação das fenol-oxidases também possibilita a degradação de uma ampla variedade de poluentes até $\mathrm{CO}_{2}$ e $\mathrm{H}_{2} \mathrm{O}$ (Barr \& Aust, 1994).

Atualmente, biorreatores airlift tem sido estudados como uma alternativa ao uso de sistemas com agitação mecânica, principalmente para o cultivo de microrganismos sensíveis ao cisalhamento. Entretanto, é possível que este problema também ocorra em airlift quando elevados fluxos de ar são aplicados (Fontana et al., 2009). No biorreator airlift, a circulação do líquido é forçada pelo próprio ar; a diferença de gás entre a zona aerada (riser) e a zona não aerada (downcomer) resulta numa diferença de densidade do líquido entre essas regiões, causando a circulação do fluido no biorreator e sendo apropriado para vários tipos de bioprocessos (Chisti, 1989).

O uso de sistemas airlift apresenta algumas vantagens, como simplicidade na construção, boa capacidade de transferência de calor e de massa, eficiente mistura e homogeneização do meio de cultivo e baixo consumo de energia (Chisti, 1989; Vial et al., 2002), sendo eficientes para aplicação em cultivos fúngicos que exigem razoáveis taxas de transferência de massa e baixas tensões de cisalhamento (Merchuk e Asenjo, 1995). Nos últimos anos, a configuração de biorreatores airlift tem sido estudada, principalmente, em termos de capacidade de transferência de oxigênio, visto que possibilita grandes vazões de ar e aumento da transferência de oxigênio gás-líquido, incluindo o uso deste sistema para o cultivo de microrganismos que formam pellets (Freitas e Teixeira, 2001; Lin et al., 2004).

Em muitas linhagens de Pleurotus, um dos cinco gêneros de fungos comestíveis mais cultivados do mundo, a adaptação a culturas líquidas é relativamente rápida (Confortin et al., 2008). Pleurotus sajor-caju apresenta excelente crescimento em processos submersos, sendo, também, um importante produtor de fenol-oxidases (Bettin et al., 2009; Bettin et al., 2011). Muitos fatores influenciam o crescimento fúngico e a produção de enzimas em biorreatores, como sua geometria e configuração, regimes de operação, agitação, aeração, temperatura, $\mathrm{pH}$, composição do meio de cultivo, proporção do inóculo e tempo de incubação (Márquez-Rocha et al., 1999; Mikiashvili et al., 2006). Diante desse contexto, o objetivo do presente trabalho foi verificar a influência de diferentes volumes de meio de cultivo e de vazões específicas de ar sobre o crescimento e a produção de fenol-oxidases de $P$. sajor-caju PS-2001 em regime descontínuo, utilizando um biorreator airlift de circulação interna.

\section{MATERIAL E MÉTODOS}

Linhagem - Pleurotus sajor-caju PS-2001, da coleção de microrganismos do IB-UCS, foi mantido em meio contendo serragem de Pinus spp., $20 \mathrm{~g}$; farelo de trigo, $20 \mathrm{~g} ; \mathrm{CaCO}_{3}, 2$ g; ágar-ágar, $20 \mathrm{~g} ; \mathrm{H}_{2} \mathrm{O}$ destilada q.s.p. 1 L. As placas com a linhagem foram mantidas em estufa a $28^{\circ} \mathrm{C}$ até completo crescimento micelial e armazenadas a $4^{\circ} \mathrm{C}$ (Bettin et al., 2009).

Composição da solução mineral - $\mathrm{KH}_{2} \mathrm{PO}_{4}, 20 \mathrm{~g}$; $\left(\mathrm{NH}_{4}\right)_{2} \mathrm{SO}_{4}, 14 \mathrm{~g} ; \mathrm{CaCl}_{2}, 3 \mathrm{~g}$; $\mathrm{MgSO}_{4} .7 \mathrm{H}_{2} \mathrm{O}, 3 \mathrm{~g}$; ureia, $3 \mathrm{~g} ; \mathrm{MnSO}_{4} \cdot \mathrm{H}_{2} \mathrm{O}, 15,6 \mathrm{mg} ; \mathrm{FeSO}_{4}, 50 \mathrm{mg} ; \mathrm{ZnSO}_{4}, 14 \mathrm{mg} ; \mathrm{CoCl}_{2}$, $20 \mathrm{mg} ; \mathrm{H}_{2} \mathrm{O}$ destilada q.s.p. 1 L (Mandels e Reese, 1957).

Inóculos - Preparados em frascos Erlenmeyer de $500 \mathrm{~mL}$ contendo $100 \mathrm{~mL}$ de meio composto por: glicose, $5 \mathrm{~g}$; caseína pura, $1,5 \mathrm{~g}$; solução mineral de nutrientes e micronutrientes, $100 \mathrm{~mL} ; \mathrm{H}_{2} \mathrm{O}$ destilada q.s.p. 1 L. Após autoclavagem, três discos de ágar de $1,5 \mathrm{~cm}$ de diâmetro foram raspados de placas com a linhagem e acrescentados ao meio (Bettin 
et al., 2009). O crescimento ocorreu sob agitação recíproca por 6 dias, a $180 \mathrm{rpm}$ e $28 \pm 2{ }^{\circ} \mathrm{C}$. A proporção dos inóculos para os cultivos em biorreator foi de 10\% (v/v) (Bettin et al., 2011).

Meio de cultivo fúngico em biorreator airlift - A composição dos meios foi baseada em glicose, $5 \mathrm{~g}$; caseína pura, $1,5 \mathrm{~g}$; ácido benzoico, $122 \mathrm{mg}$; $\mathrm{CuSO}_{4}, 100 \mathrm{mg}$; solução mineral de nutrientes e micronutrientes, $100 \mathrm{~mL} ; \mathrm{H}_{2} \mathrm{O}$ destilada q.s.p. 1 L. Os meios foram autoclavados por 20 minutos, juntamente com a cuba do biorreator. Em todas as condições, antiespumante à base de silicone foi adicionado, quando necessário (Bettin et al., 2011).

Condições de cultivo em biorreator airlift de circulação interna - Utilizou-se um biorreator airlift de volume nominal de $6 \mathrm{~L}$ com dimensões de $75 \mathrm{~cm}$ de altura e $11 \mathrm{~cm}$ de diâmetro; o tubo interno (riser) possui $34 \mathrm{~cm}$ de altura e $7 \mathrm{~cm}$ de diâmetro. Diferentes volumes de meio de cultivo (4, 4,5 e $5 \mathrm{~L}$ ) foram testados utilizando-se vazão de ar de 1,0 L.min ${ }^{-1}$. Os ensaios em que foram testadas diferentes aerações $\left(1,1,5\right.$ e $\left.2 \mathrm{~L} \cdot \mathrm{min}^{-1}\right)$ foram realizados em volume de 4,5 $\mathrm{L}$ de meio de cultivo. As vazões específicas de ar foram fixadas no início dos cultivos, não sendo alteradas durante o processo, em todos os experimentos realizados, com percentual de saturação em oxigênio dissolvido flutuando livremente. Os ensaios foram conduzidos em regime descontínuo, $\mathrm{pH} 6,5$ a $28 \pm 1^{\circ} \mathrm{C}$, durante 90 horas.

Atividades enzimáticas - Os substratos utilizados nas quantificações enzimáticas foram ABTS para lacases (Wolfenden e Willson, 1982); ABTS e $\mathrm{H}_{2} \mathrm{O}_{2}$ para peroxidases totais (Heinzkill et al., 1998); vermelho de fenol, $\mathrm{MnSO}_{4}$ e $\mathrm{H}_{2} \mathrm{O}_{2}$ para manganês peroxidases (Kuwahara et al., 1984); álcool veratrílico para oxidases do álcool veratrílico (Bourbonnais e Paice, 1988); álcool veratrílico e $\mathrm{H}_{2} \mathrm{O}_{2}$ para lignina peroxidases (Tien e Kirk, 1984).

Determinação das concentrações de substrato e de biomassa fúngica - $\mathrm{O}$ consumo do substrato (glicose) utilizado nos cultivos foi quantificado com a utilização do reagente DNS (ácido 3,5-dinitrosalicílico) e curva padrão de glicose, de acordo com Miller (1959). A concentração celular foi mensurada por gravimetria, em cadinhos de porcelana.

\section{RESULTADOS E DISCUSSÃO}

Os dados apresentados neste trabalho se referem a ensaios conduzidos em biorreator airlift de circulação interna utilizando diferentes volumes de meio de cultivo (4, 4,5 e $5 \mathrm{~L}$ com aeração de $\left.1 \mathrm{~L} \cdot \mathrm{min}^{-1}\right)$ e vazões de ar (1, 1,5 e $21 \mathrm{~L} \cdot \mathrm{min}^{-1}$ em 4,5 L de meio). Em todas as condições testadas, buscou-se avaliar a síntese de fenol-oxidases de P. sajor-caju PS-2001, assim como o crescimento micelial e os consumos de substrato e de oxigênio dissolvido, durante 90 horas de processo.

Na Figura 1, são mostrados os perfis atividade de lacases, que representam as principais enzimas produzidas pelo fungo utilizado. Com relação à produção em diferentes volumes de meio de cultivo (Figura 1A), observa-se que níveis elevados de atividade enzimática foram detectados com 5 e 4,5 L de meio reacional, atingindo picos de 132 e 96 U. $\mathrm{mL}^{-1}$, respectivamente, ambos em 90 horas de incubação; a atividade observada com $4 \mathrm{~L}$ de meio de cultivo mostrou níveis inferiores a $20 \mathrm{U} \cdot \mathrm{mL}^{-1}$. Sob diferentes vazões específicas de ar (Figura 1B), a maior atividade de lacases foi obtida com 1,5 L. $\mathrm{min}^{-1} \mathrm{de}$ ar, atingindo 156 U.mL ${ }^{-1}$ também em 90 horas de cultivo; com aerações de 1 e 2 L.min ${ }^{-1}$, as atividades máximas de lacases foram de 96 e 84 U. $\mathrm{mL}^{-1}$, respectivamente. 

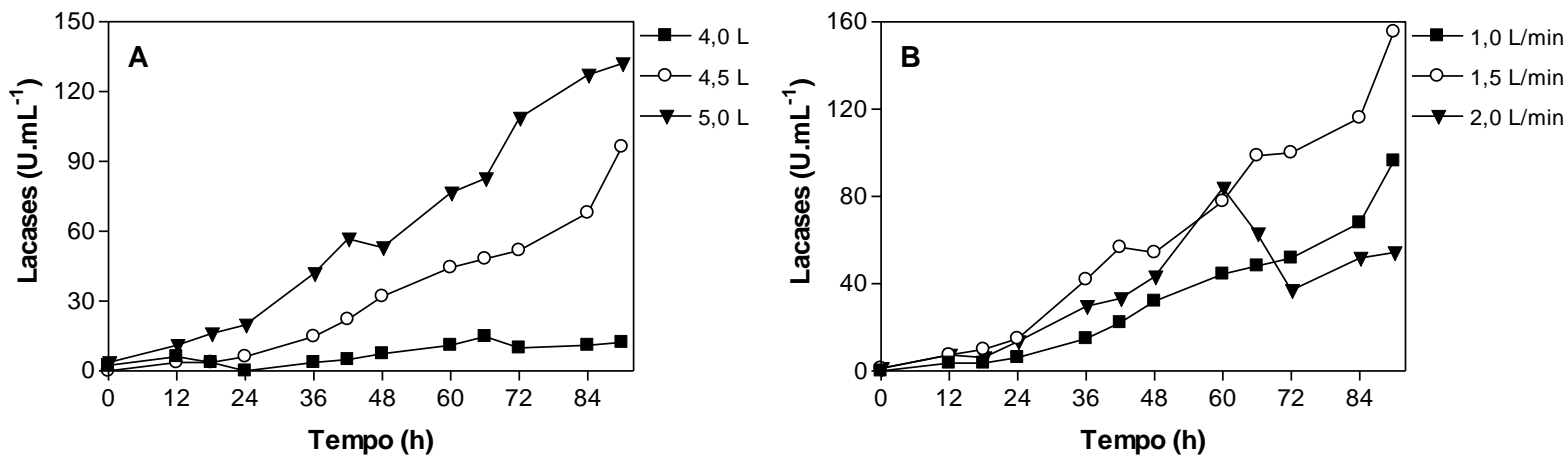

Figura 1 - Atividades de lacases em função do tempo obtidas durante cultivos submersos de

Pleurotus sajor-caju PS-2001 realizados em biorreator airlift de circulação interna sob diferentes volumes de meio de cultivo (A) e vazões de ar (B) em pH 6,5 a $28^{\circ} \mathrm{C}$.

A Tabela 1 mostra as máximas atividades enzimáticas das fenol-oxidases quantificadas durante os ensaios. No teste em que foi detectada a máxima produção de lacases (aeração de 1,5 L.min ${ }^{-1}$ em 4,5 L de meio), também foram observados os títulos máximos de peroxidases totais e de manganês peroxidases $(\mathrm{MnP})$, com picos de 31 e $21 \mathrm{U}^{\mathrm{mL}} \mathrm{mL}^{-1}$, respectivamente. Nesta condição, também foi detectada baixa atividade de oxidases do álcool veratrílico $(\mathrm{OAV})$. Outra condição favorável à produção de $\mathrm{MnP}$ foi a utilização de $4 \mathrm{~L}$ de meio de cultivo com aeração de $1 \mathrm{~L} \cdot \mathrm{min}^{-1}$, que proporcionou atividade máxima de $17 \mathrm{U} \cdot \mathrm{mL}^{-1}$.

Tabela 1 - Atividades enzimáticas máximas de fenol-oxidases obtidas durante cultivos submersos de Pleurotus sajor-caju PS-2001 realizados em biorreator airlift de circulação interna sob diferentes volumes de meio de cultivo e vazões de ar em $\mathrm{pH} 6,5$ a $28^{\circ} \mathrm{C}$

\begin{tabular}{|c|c|c|c|c|c|c|}
\hline \multirow{2}{*}{ ENZIMAS } & \multicolumn{3}{|c|}{ Volume de meio de cultivo $(L)$} & \multicolumn{3}{|c|}{ Vazão de ar (L.min $\left.{ }^{-1}\right)$} \\
\hline & 4,0 & 4,5 & 5,0 & 1,0 & 1,5 & 2,0 \\
\hline $\operatorname{Lac}_{\text {máx }}\left(\mathbf{U}_{\text {.mL }} \mathbf{1}^{-1}\right)$ & 14,8 & 96,3 & 132,1 & 96,3 & 155,6 & 83,9 \\
\hline Tempo (h) & 66 & 90 & 90 & 90 & 90 & 60 \\
\hline $\operatorname{Per}_{\text {máx }}\left(\right.$ U.mL $\left.^{-1}\right)$ & 2,47 & 9,88 & 12,3 & 9,88 & 30,9 & 11,1 \\
\hline Tempo (h) & 90 & 66 & 90 & 66 & 90 & 36 \\
\hline $\mathrm{MnP}_{\text {máx }}\left(\mathrm{U}_{\cdot \mathrm{mL}^{-1}}\right)$ & 17,4 & 9,79 & 7,68 & 9,79 & 21,2 & 3,51 \\
\hline Tempo (h) & 24 & 90 & 36 & 90 & 84 & 72 \\
\hline $\operatorname{LiP}_{\text {máx }}\left(\right.$ U.mL $\left.^{-1}\right)$ & ND & ND & ND & ND & ND & ND \\
\hline Tempo (h) & --- & --- & --- & --- & --- & --- \\
\hline$O A V_{\text {máx }}\left(U \cdot m L^{-1}\right)$ & ND & ND & ND & ND & 0,07 & ND \\
\hline Tempo (h) & --- & --- & --- & --- & 12 & --- \\
\hline
\end{tabular}

Legenda: $\mathbf{L a c}_{\text {máx }}$ (atividade máxima de lacases), $\mathbf{P e r}_{\text {máx }}$ (atividade máxima de peroxidases totais), $\mathbf{M n P _ { \text { máx } }}$ (atividade máxima de manganês peroxidases), LiP $\mathbf{P}_{\text {máx }}$ (atividade máxima de lignina peroxidases), $\mathbf{O A} \mathbf{V}_{\text {máx }}$ (atividade máxima de oxidases do álcool veratrílico), ND (atividade enzimática não detectada).

Lignina peroxidases (LiP) não foram observadas em nenhuma das condições testadas (Tabela 1). Porém, a produção de LiP requer condições específicas, como limitação de nitrogênio e saturação de oxigênio (Saparrat et al., 2002). Essa constatação pode explicar a ausência desta enzima nas condições testadas, uma vez que atividades de LiP e OAV já foram detectadas durante cultivos submersos de P. sajor-caju PS-2001 realizados em biorreator com 
agitação mecânica (Bettin et al., 2011). Bourbonnais e Paice (1988), em estudos realizados com P. sajor-caju 405, observaram atividade máxima de OAV de 1 U.mL ${ }^{-1}$ em 24 dias.

Utilizando o substrato dimetoxifenol para a detecção enzimática, Liu et al. (2013) verificaram atividades de lacases de $72 \mathrm{U}_{\mathrm{mL}}^{-1}$ no sexto dia de cultivo de Pycnoporus sp. em biorreator airlift de $65 \mathrm{~L}$, operado com aeração de $30 \mathrm{~L} \cdot \mathrm{min}^{-1} \mathrm{em} \mathrm{pH}$ inicial de 5,0 a $30^{\circ} \mathrm{C}$. Contudo, utilizando o mesmo substrato do presente trabalho (ABTS) em meio composto por glicerol, Rodríguez Couto et al. (2006) observaram atividades máximas de 19 U.mL ${ }^{-1}$ de lacases em 24 dias de cultivo de Trametes hirsuta em airlift com volume operacional de $6 \mathrm{~L}$, $\mathrm{pH}$ controlado em 4,5 e suprimento de ar de $1 \mathrm{vvm}$. Essas comparações sugerem que $P$. sajorсаju PS-2001 possui elevado potencial de produção de lacases em biorreatores do tipo airlift, fato evidenciado pelas elevadas atividades enzimáticas obtidas neste trabalho (Figura 1).

Na Tabela 2, estão resumidos os principais resultados obtidos nos cultivos. Os dados referentes à enzima $\left(\mathrm{Y}_{\mathrm{E} / \mathrm{S}}\right.$ e $\left.\mathrm{P}_{\mathrm{E}}\right)$ correspondem ao tempo em que foi detectado o pico de atividade de lacases ( $\left.\mathrm{Lac}_{\text {máx }}\right)$, enquanto os dados referentes à biomassa $\left(\mathrm{Y}_{\mathrm{X} / \mathrm{S}} \mathrm{e} \mathrm{P}_{\mathrm{X}}\right)$ correspondem ao tempo em que foi observado o pico de concentração celular $\left(\mathrm{X}_{\text {máx }}\right)$; o fator de rendimento específico $\left(\mathrm{Y}_{\mathrm{E} / \mathrm{X}}\right)$ relaciona a máxima atividade de lacases com a máxima concentração celular. A produtividade volumétrica $\left(\mathrm{P}_{\mathrm{E}}\right)$ foi superior a $1 \mathrm{U} \cdot \mathrm{mL}^{-1} \cdot \mathrm{h}^{-1} \mathrm{em}$ todos os testes realizados, com exceção de $4 \mathrm{~L}$ de meio com aeração de 1 L.min ${ }^{-1}$. Com relação ao rendimento enzimático $\left(\mathrm{Y}_{\mathrm{E} / \mathrm{S}}\right)$, os melhores resultados foram obtidos também no teste em que foi detectada a mais elevada atividade de lacases $\left(4,5 \mathrm{~L}\right.$ de meio com aeração de 1,5 L. $\left.\mathrm{min}^{-1}\right)$. A produtividade $\left(\mathrm{P}_{\mathrm{X}}\right)$ foi superior nos testes que mostraram elevada biomassa micelial, sendo comparável nas demais condições. O rendimento celular $\left(\mathrm{Y}_{\mathrm{X} / \mathrm{S}}\right)$ também foi superior no teste de mais elevada atividade de lacases, devido à precocidade de detecção do pico de crescimento, combinado com baixo consumo de substrato em 36 horas. $\mathrm{O}$ fator de rendimento específico $\left(\mathrm{Y}_{\mathrm{E} / \mathrm{X}}\right)$ mostra que a relação entre síntese de lacases e formação de biomassa foi superior no ensaio de maior atividade de lacases, sugerindo que elevada síntese enzimática não está relacionada com intenso crescimento, nas condições testadas.

Tabela 2 - Resultados gerais obtidos durante cultivos submersos de

Pleurotus sajor-caju PS-2001 realizados em biorreator airlift de circulação interna sob diferentes volumes de meio de cultivo e vazões de ar em $\mathrm{pH} 6,5$ a $28^{\circ} \mathrm{C}$

\begin{tabular}{|c|c|c|c|c|c|c|}
\hline \multirow{2}{*}{ PARÂMETROS } & \multicolumn{3}{|c|}{ Volume de meio de cultivo (L) } & \multicolumn{3}{|c|}{ Vazão de ar (L.min $\left.{ }^{-1}\right)$} \\
\hline & 4,0 & 4,5 & 5,0 & 1,0 & 1,5 & 2,0 \\
\hline $\operatorname{Lac}_{\text {máx }}\left(\right.$ U.mL $\left.^{-1}\right)$ & 14,8 & 96,3 & 132,1 & 96,3 & 155,6 & 83,9 \\
\hline Tempo (h) & 66 & 90 & 90 & 90 & 90 & 60 \\
\hline $\mathbf{P}_{\mathrm{E}}\left(\mathrm{U} \cdot \mathrm{mL}^{-1} \cdot \mathrm{h}^{-1}\right)$ & 0,187 & 1,070 & 1,427 & 1,070 & 1,715 & 1,379 \\
\hline$Y_{E / S}\left(U_{. g}{ }^{-1}\right)$ & 1849 & 49258 & 25210 & 49258 & 52789 & 26216 \\
\hline$X_{\text {máx }}\left(\right.$ g.L $\left.^{-1}\right)$ & 3,62 & 1,24 & 1,87 & 1,24 & 1,26 & 4,59 \\
\hline Tempo (h) & 72 & 60 & 90 & 60 & 36 & 72 \\
\hline$P_{X}\left(g . L^{-1} \cdot h^{-1}\right)$ & 0,048 & 0,018 & 0,018 & 0,018 & 0,029 & 0,061 \\
\hline$Y_{X / S}\left(g \cdot g^{-1}\right)$ & 0,504 & 1,586 & 0,326 & 1,586 & 4,088 & 0,625 \\
\hline$Y_{E / X}\left(U \cdot g^{-1}\right)$ & 4,088 & 77,661 & 70,642 & 77,661 & 123,492 & 18,279 \\
\hline
\end{tabular}

Legenda: $\mathbf{L a c}_{\operatorname{máx}}$ (máxima atividade de lacases), $\mathbf{P}_{\mathbf{E}}$ (produtividade volumétrica de lacases), $\mathbf{Y}_{\mathbf{E} / \mathbf{s}}$ (fator de rendimento de substrato em atividade de lacases), $\mathbf{X}_{\operatorname{máx}}$ (máxima concentração celular), $\mathbf{P}_{\mathbf{X}}$ (produtividade volumétrica de biomassa), $\mathbf{Y}_{\mathbf{X} / \mathbf{S}}$ (fator de rendimento de substrato em células), $\mathbf{Y}_{\mathbf{E} / \mathbf{X}}$ (fator de rendimento específico relacionando a máxima atividade de lacases com a máxima concentração celular). 
Embora o perfil cinético não seja apresentado, em todos os experimentos foram observadas quedas graduais nos níveis de substrato (glicose) e de oxigênio dissolvido, o que é uma característica de microrganismos aeróbios em cultivos submersos. Liu et al. (2013) relataram que lacases são as principais enzimas produzidas por Pycnoporus sp. em cultivos realizados em biorreator airlift, observando aumento de biomassa e concomitante decréscimo nos níveis de $\mathrm{pH}$ e de oxigênio dissolvido.

A mistura e a circulação do meio, em todas as condições testadas, foram consideradas excelentes, não apresentando zonas estagnadas ou quaisquer outros problemas operacionais durante todo o período de incubação; além disso, a viscosidade aparente do caldo praticamente não foi alterada. Segundo Fontana et al. (2009), o aumento da viscosidade no meio de cultura representa uma dificuldade adicional para a operação de sistemas airlift em bioprocessos para a produção enzimática. Utilizando biorreatores semelhantes, estudos realizados com Aspergillus oryzae para a produção de poligalacturonases (Fontana e Silveira, 2012) e com Penicillium echinulatum para a produção de celulases e xilanases (Ritter et al., 2013), mostraram grande aumento da viscosidade do meio devido ao crescimento fúngico e à adição de indutores, necessitando de aumento na aeração para a manutenção da circulação e da mistura dos caldos enzimáticos, com consequente efeito sobre a transferência de oxigênio e a produtividade volumétrica. Entretanto, os resultados obtidos com $P$. sajor-caju PS-2001 em biorreator airlift corroboram as informações de Rancaño et al. (2003) e Domínguez et al. (2007), que estudaram a produção de lacases por Trametes versicolor em sistemas airlift de 2 L utilizando bateladas sucessivas, durante 40 dias e 44 dias, respectivamente, com aeração de 1 L.min ${ }^{-1}$ a $30^{\circ} \mathrm{C}$, sem problemas operacionais durante os processos. Os autores afirmaram que a configuração do biorreator foi apropriada para a obtenção de elevadas atividades enzimáticas e para a manutenção de pellets de tamanho regular (Rancaño et al., 2003).

\section{CONCLUSÕES}

Os resultados obtidos neste trabalho mostram que a aplicação do sistema airlift para o cultivo de $P$. sajor-caju PS-2001 em processo submerso é eficiente tanto para a síntese enzimática quanto para o crescimento fúngico. Dentre as fenol-oxidases produzidas por este microrganismo, destacam-se as lacases, que podem alcançar elevadas atividades nesse tipo de biorreator, dependendo das condições operacionais adotadas. Outro fator relevante a ser ressaltado é a facilidade de operação, combinada com excelente mistura e homogeneização do meio reacional, sem alteração da viscosidade aparente durante o crescimento micelial. Para a continuidade dos estudos nessa linha de pesquisa, outros experimentos estão sendo desenvolvidos visando esclarecer a influência dos diversos fatores que afetam a atividade enzimática e o crescimento fúngico em biorreator airlift, incluindo variação nos parâmetros operacionais e na composição dos meios de cultivo.

\section{REFERÊNCIAS}

BARR, D.P.; AUST, S.D. Mechanism white rot fungi use to degrade pollutants. Environ. Sci. Technol., v. 28, p. 78-87, 1994.

BETTIN, F.; MONTANARI, Q.; CALLONI, R.; GAIO, T.A.; SILVEIRA, M.M.; DILLON, A.J.P. Production of laccases in submerged process by Pleurotus sajor-caju PS-2001 in relation to carbon and organic nitrogen sources, antifoams and Tween 80. J. Ind. Microbiol. Biotechnol., v. 36, p. 1-9, 2009. 
BETTIN, F.; ROSA, L.O.; MONTANARI, Q.; CALLONI, R.; GAIO, T.A.; MALVESSI, E.; SILVEIRA, M.M.; DILLON, A.J.P. Growth, kinetics, production, and characterization of extracellular laccases from Pleurotus sajor-caju PS-2001. Process Biochem., v. 46, p. 758-764, 2011.

BOURBONNAIS, R.; PAICE, M.G. Veratryl alchool oxidases from the lignin-degrading basidiomycete Pleurotus sajor-caju. Biochem. J., v. 255, p. 445-450, 1988.

CANET, R.; BIRNSTINGL, J.G.; MALCOLM, D.G.; LOPEZ-REAL, J.M.; BECK, A.J. Biodegradation of polycyclic aromatic hydrocarbons (PAHs) by native microflora and combinations of white-rot fungi in a coal-tar combinated soil. Bioresour. Technol., v. 76, p. 113$117,2001$.

CHISTI, Y. Airlift bioreactors. London: Elsevier Science Publishers, 1989.

CONFORTIN, F.G.; MARCHETTO; R.; BETTIN, F.; CAMASSOLA, M.; SALVADOR, M.; DILLON, A.J.P. Production of Pleurotus sajor-caju strain PS-2001 biomass in submerged culture. J. Ind. Microbiol. Biotechnol., v. 35, p. 1149-1155, 2008.

COUTO, S.R.; HERRERA, J.L.T. Industrial and biotechnological applications of laccases: a review. Biotechnol. Adv., v. 24, p. 500-513, 2006.

DHAWAN, S.; LAL, R.; HANSPAL, M.; KUHAD, R.C. Effect of antibiotics on growth and laccase production from Cyathus bulleri and Pycnoporus cinnabarinus. Bioresour. Technol., v. 96, p. 1415-1418, 2005.

DOMÍNGUEZ, A.; GÓMEZ, J.; LORENZO, M.; SANROMÁN, A. Enhanced production of laccase activity by Trametes versicolor immobilized into alginate beads by the addition of different inducers. World J. Microbiol. Biotechnol., v. 23, p. 367-373, 2007.

FONTANA, R.C.; POLIDORO, T.A.; SILVEIRA, M.M. Comparison of stirred tank and airlift bioreactors in the production of polygalacturonases by Aspergillus oryzae. Bioresour. Technol., v. 100, p. 4493-4498, 2009.

FONTANA, R.C.; SILVEIRA, M.M. Production of polygalacturonases by Aspergillus oryzae in stirred tank and internal- and external-loop airlift reactors. Bioresour. Technol., v. 123, p. 157-163, 2012.

FREITAS, C.; TEIXEIRA, J.A. Oxygen mass transfer in a high solids loading three-phase internalloop airlift reactor. Chem. Eng. J. v. 84, p. 57-61, 2001.

GILL, P.K.; ARORA, D.S. Effect of culture conditions on manganese peroxidase production and activity by some white rot fungi. J. Ind. Microbiol. Biotechnol., v. 30, p. 28-33, 2003.

HEINZKILL, M.; BECH, L.; HALKIER, T.; SCHNEIDER, P.; ANKE, T. Characterization of laccases and peroxidases from wood-rotting fungi (Family Coprinaceae). Appl. Environ. Microbiol., v. 64, p. 1601-1606, 1998.

KUWAHARA, M.; GLENN, J.K.; MORGAN, M.A.; GOLD, M.H. Separation and characterization of two extracellular $\mathrm{H}_{2} \mathrm{O}_{2}$-dependent oxidases from ligninolytic cultures of Phanerochaete chrysosporium. FEBS Lett., v. 169, p. 247-250, 1984.

LIN, J.; HAN, M.; WANG, T.; ZHANG, T.; WANG, J.; JIN, Y. Influence of the gas distributor on the local hydrodynamic behavior of an external loop airlift reactor. Chem. Eng. J., v. 102, p. 51-59, 2004.

LIU, J.; CAI, Y.; LIAO, X.; HUANG, Q.; HAO, Z.; HU, M.; ZHANG, D.; LI, Z. Efficiency of laccase production in a $65-\mathrm{L}$ air-lift reactor for potential green industrial and environmental application. $J$. Cleaner Production, v. 39, p. 154-160, 2013. 
MANDELS, M.; REESE, E.T. Induction of cellulase in Trichoderma viride as influenced by carbon source and metals. J. Bacteriol., v. 73, p. 269-278, 1957.

MÁRQUEZ-ROCHA, F.J.; GUILLÉN, G.K.; SÁNCHEZ, J.E.; VÁZQUEZ-DUHALT, R. Growth characteristics of Pleurotus ostreatus in bioreactors. Biotechnol. Tech., v. 13, p. 29-32, 1999.

MERCHUK, J.C.; ASENJO, J.A. Fundamentals of bioreactor design. Bioprocess Technol., v. 21, p. 139-205, 1995.

MIKIASHVILI, N.; WASSER, S.P.; NEVO, E.; ELISASHVILI, V. Effects of carbon and nitrogen sources on Pleurotus ostreatus ligninolytic enzyme activity. World J. Microbiol. Biotechnol., v. 22, p. 999-1002, 2006.

MILLER, G.L. Use of dinitrosalicilic acid reagent for determination of reducing sugar. Anal. Chem., v. 31, p. 426-428, 1959.

MIN, K.L.; KIM, Y.H.; KIM, Y.W.; JUNG, H.S.; HAH, Y.C. Characterization of a novel laccase produced by the wood-rotting fungus Phellinus ribis. Arch. Biochem. Biophys., v. 392, p. 279-286, 2001.

MUNARI, F.M.; GAIO, T.A.; DILLON, A.J.P. Phenol degradation and colour removal in submerged culture of Pleurotus sajor-caju with paper mill effluents. Biocatal. Biotransform., v. 25, p. 24-28, 2007.

RANCAÑO, G.; LORENZO, M.; MOLARES, N.; COUTO, S.R.; SANROMÁN, M.A. (2003). Production of laccase by Trametes versicolor in an airlift fermentor. Process Biochem., v. 39, p. 467-473, 2003.

RITTER, C.E.T.; FONTANA, R.C.; CAMASSOLA, M.; SILVEIRA, M.M.; DILLON, A.J.P. The influence of sorbitol on the production of cellulases and xylanases in an airlift bioreactor. Bioresour. Technol., v. 148, p. 86-90, 2013.

RODRÍGUEZ COUTO, S.; RODRÍGUEZ, A.; PATERSON, R.R.M.; LIMA, N.; TEIXEIRA, J.A. Laccase activity from the fungus Trametes hirsuta using an air-lift bioreactor. Lett. Appl. Microbiol., v. 42, p. 612-616, 2006.

SAPARRAT, M.C.N.; MARTÍNEZ, M.J.; CABELLO, M.N.; ARAMBARRI, A.M. Screening for ligninolytic enzymes in autochthonous fungal strains from Argentina isolated from different substrata. Rev. Iberoam. Micol., v. 19, p. 181-185, 2002.

SCHMITT, S.; SOUZA, R.; BETTIN, F.; DILLON, A.J.P.; VALLE, J.A.B.; ANDREAUS, J. Decolorization of aqueous solutions of disperse textile dyes by oxidoreductases. Biocatal. Biotransform., v. 30, p. 48-56, 2012.

TIEN, M.; KIRK, T.K. Lignin-degrading enzyme from Phanerochaete chrysosporium: Purification, characterization, and catalytic properties of a unique $\mathrm{H}_{2} \mathrm{O}_{2}$-requiring oxygenase. Proc. Natl. Acad. Sci. USA, v. 81, p. 2280-2284, 1984.

VIAL, C.; PONCIN, S.; WILD, G.; MIDOUX, N. Experimental and theoretical analysis of the hydrodynamics in the riser of an extemal loop airlift reactor. Chem. Eng. Sci., v. 57, p. 4745-4762, 2002.

WOLFENDEN, B.S.; WILLSON, R.L. Radical-cations as reference chromogens in the kinetic studies of one-electron transfer reactions: pulse radiolysis studies of 2,2'-azinobis-(3-ethylbenzthiazoline6-sulphonate). J. Chem. Soc. Perkin Trans. II, v. 02, p. 805-812, 1982.

Apoio: FAPERGS, CAPES, CNPq e UCS. 